\title{
Experimental Study on Dry Electrostatic Cooling in Turning
}

\author{
Hui Wang ${ }^{1,2, a}$, Xiulin $\mathrm{Ji}^{1,2, b}$, Fusheng $\mathrm{Ni}^{1,2, \mathrm{c}}$ \\ ${ }^{1}$ College of Mechanical and Electrical Engineering, Hohai University, Changzhou, CHN \\ ${ }^{2}$ Engineering Research Center of Dredging Technology of Ministry of Education, \\ Hohai University, Changzhou, CHN \\ awanghui@hhuc.edu.cn, bxiulinji@gmail.com, cfushengni@163.com
}

Keywords: Green cutting, Dry electrostatic cooling, Cutting force, Cutting temperature, Tool wear.

\begin{abstract}
In recent years, environmental concerns call for the reduced of cutting fluids in metal machining. The green manufacturing techniques are investigated to achieve the objective. In this paper, for the aim of green cutting, the dry electrostatic cooling was applied instead of cutting fluid. The effects of dry electrostatic cooling, compressed air and dry cutting on cutting force, thrust force, cutting temperature, chip formation and tool wear have been examined in turning of AISI1045 steels with carbide tools P10. The experiments were performed at different cutting depths and feeds. The results indicated that the lower cutting force and cutting temperature was gained with applying of dry electrostatic cooling, the values were reduced about 8 percent and 10 percent compared to dry cutting respectively, it is also advantage in forming acceptable chips. In addition, tool wear was decreased in dry electrostatic cooling. The research results show that the production efficiency was increased and clean production was achieved in metal cutting associated with dry electrostatic cooling.
\end{abstract}

\section{Introduction}

During the metal cutting processes, cutting fluids are used to reduce the negatively effects of heat and friction on both tool and workpiece. The cutting fluids are employed to decrease cutting force and cutting temperature, prevent the formation of built-up edge, generally prolong tool life, enhance the surface finish and remove chip from the cutting area[1]. Unfortunately, there are some harmful chemical composition in conventional cutting fluids, which cause environmental and health problems. On the one hand, the process-generated pollution in machining has been mainly coming from waste cutting fluids because of large-scale application. On the other hand, the disposal of cutting fluids became important environmental and economical problem, due to the cost of dealing with disposal is expensive and increases the production costs. With the development of the societal environmental awareness, regulations and laws, the negatively effects of conventional cutting fluids for environment and health should been considered in metal machining.

In the 21th century, the machining technology is desired to be clean, ecological and low energy cost. In recent decades, machining without application of any cutting fluids (dry cutting or green cutting) is becoming more and more popular due to concern of the safety of the environment and health[2]. But there are still some problems about dry cutting in metal machining processes, one of them is the high temperature in cutting zone which negatively affects tool life, especially in the case of dry cutting difficult-to-cut materials. Therefore, the new green cutting technique, which is ecological, economical and superior cooling and lubricating parameters, has become focus in metal machining. In recent years, there are some new green cutting techniques, such as minimum quantity of lubricant[3], spray cooling[4], cryogenic cooling[5], different gas application[6], water vapor[7] and so on. All of them have positively effect of machining process, can decrease the cutting force and cutting temperature, reduce the tool wear and increase the production efficiency.

Dry electrostatic cooling (DEC)[8] in machining is one of the new green techniques, which is cheap, clean, no-pollution, eco-friendly and no recovery. The application of dry electrostatic cooling in machining avoids the negatively effects of conventional cutting fluids for environment and health, achieves the aim of green machining. This technique consists of the injection of ionized gas jet with a large number of ions and ozone molecular. Previous studies[8-12] proved the advantages of this 
method, and there are several successful experiences when it is used in the machining of different materials. In this study, the dry electrostatic cooling was applied instead of cutting fluid. The effects of dry electrostatic cooling on cutting force, thrust force, cutting temperature and chip formation have been examined in turning of AISI1045 steel with carbide tool P10.

\section{Experimental}

The cutting experimental system consists of the compressed air supply setup, the high-voltage power supply, corona discharger (ionizer) and nozzle. The gas supplied by compressed air machine through the control valve and flowmeter, get into the ionizer, where the corona discharger takes place. The energy is provided by the high-voltage power supply. The generated ions and ozone are transported to the cutting zone by feeding compressed air through the ionizer and nozzle and play the role of coolant and lubricant. The schematic of experimental system is shown in Fig.1. The experimental photo is shown in Fig.2.

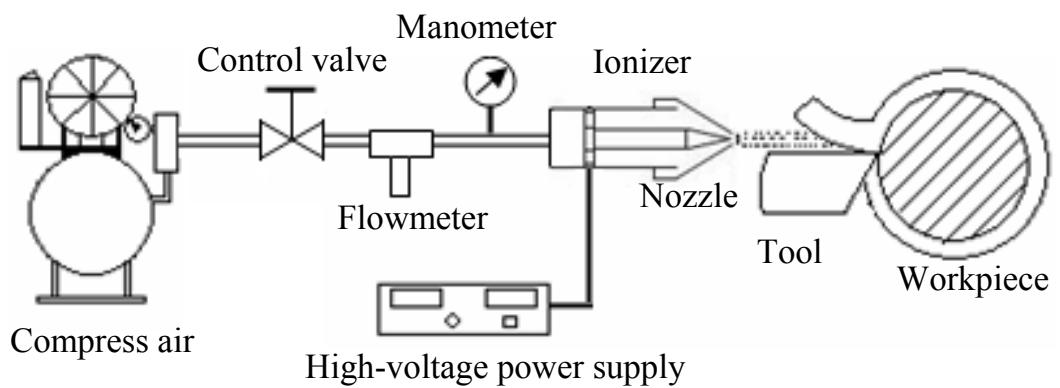

Fig.1 Schematic of experimental system on dry electrostatic cooling

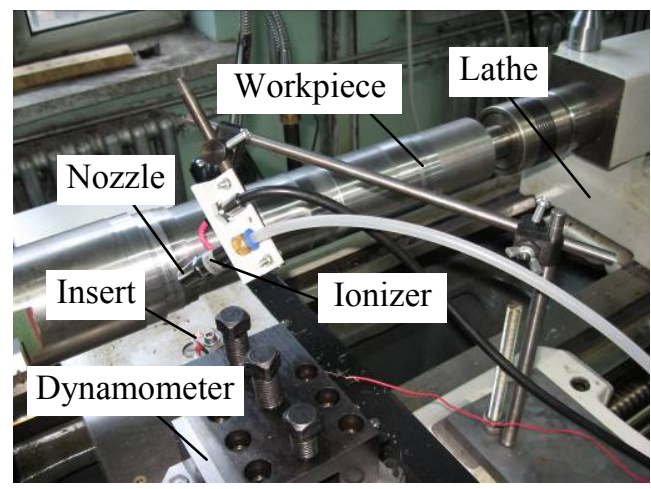

Fig.2 Experimental photo

The cutting experimental study was proposed in single-factor method under dry electrostatic cooling and dry cutting. The cutting force is measured by Kislter 9257A dynamometer and the cutting temperature is measured by the work-tool thermocouple and the function recorder. The experiment was set up on a universal lathe machine CA6140. The inserts is carbide tool P10 and the workpiece is AISI1045 steel. The tool angles are shown in Table 1. Dry electrostatic cooling and dry cutting were carried out under the same cutting parameters. During dry electrostatic cooling applications, the out voltage of the high-voltage power supply was $-5 \mathrm{Kv}$, the distance between the nozzle and cutting zone was $30 \mathrm{~mm}$, the diameter of the nozzle was $3 \mathrm{~mm}$, the pressure of the gas is $0.2-0.3 \mathrm{MPa}$ and its temperature is $18^{\circ} \mathrm{C}$.

Table 1 Experimental tool angles

\begin{tabular}{c|c|c|c|c}
\hline$\gamma_{\mathrm{o}}$ & $\alpha_{\mathrm{o}}$ & $\kappa_{\mathrm{r}}$ & $\kappa_{\mathrm{r}}^{\prime}$ & $\lambda_{\mathrm{s}}$ \\
\hline $14^{\circ}$ & $6^{\circ}$ & $75^{\circ}$ & $15^{\circ}$ & $-6^{\circ}$ \\
\hline
\end{tabular}

\section{Results and discussion}

Cutting force and thrust force. Fig. 3 and Fig. 4 shows the variation of cutting force and thrust force with depth of cut and feed respectively under specified conditions. It is observed that cutting 
force and thrust force is lower during dry electrostatic cooling (DEC) comparedwith dry cutting, the values were reduced about 8 percent respectively. Due to the electrostatic cooling is the injection of ionized gas with a large number of ions and a few ozone, it can easily penetrate into the tool-chip interface, reform the friction status and decrease the cutting force and thrust force.
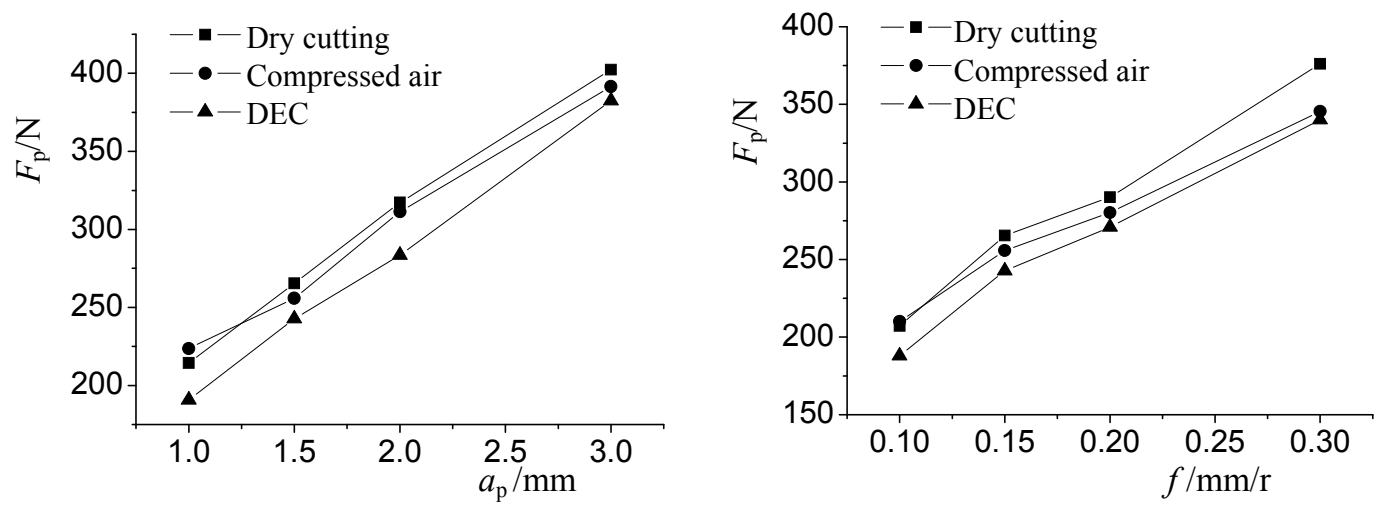

$v_{\mathrm{c}}=96.1 \mathrm{~m} / \mathrm{min}, f=0.15 \mathrm{~mm} / \mathrm{r}$ $v_{\mathrm{c}}=96.1 \mathrm{~m} / \mathrm{min}, a_{\mathrm{p}}=1.5 \mathrm{~mm}$

Fig.4 Compared with thrust force $F_{\mathrm{p}}$

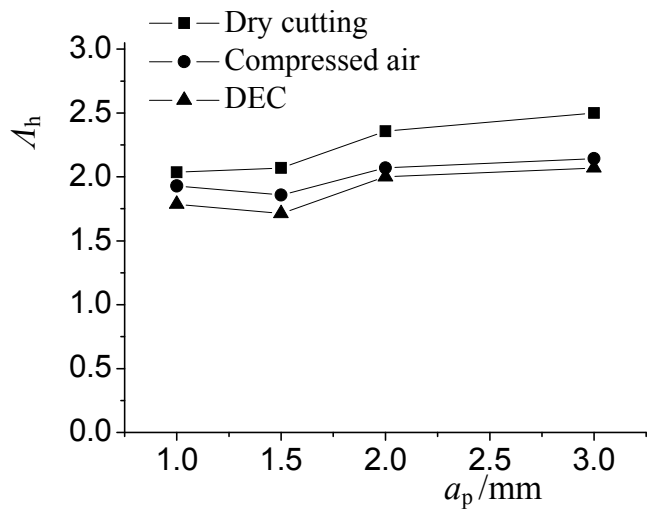

$v_{\mathrm{c}}=96.1 \mathrm{~m} / \mathrm{min}, f=0.15 \mathrm{~mm} / \mathrm{r}$

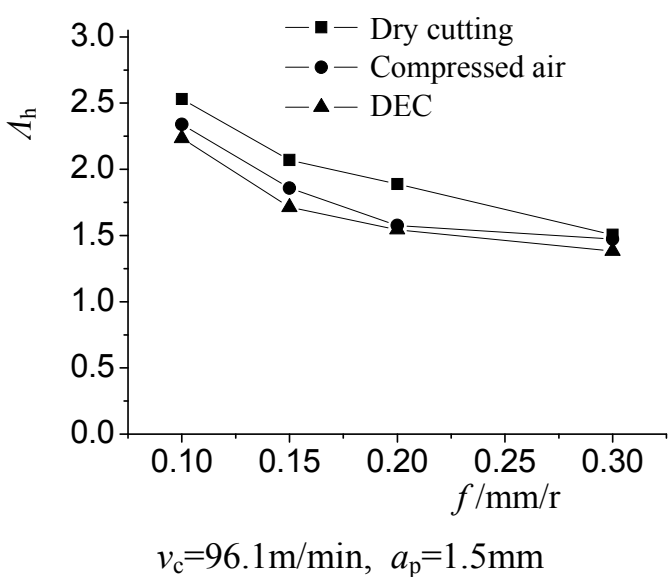

$v_{\mathrm{c}}=96.1 \mathrm{~m} / \mathrm{min}, a_{\mathrm{p}}=1.5 \mathrm{~mm}$

Fig. 5 Vompared with chip deformation coefficient $\Lambda_{\mathrm{h}}$

Chip deformation coefficient. The variation of chip deformation coefficient in different depth of cut and feed is shown in Fig.5. It is indicated that lower chip deformation coefficient with the application of dry electrostatic cooling compared with dry cutting. The reason is that the friction between the rake face and the chip is reduced, the shear angle increased and the chip deformation coefficient is recuded under the dry electrostatic cooling.

Cutting temperature. The variation of cutting temperature in different depth of cut and feed is shown in Fig.6. It is observed that lower cutting temperature is possible during dry electrostatic cooling than dry cutting. The cutting temperature was reduced about 10 percent compared with dry cutting. On the one hand, the injection of ionized gas and compressed air increased the capacity of convection heat transfer, on the other hand, the ions and ozone during dry electrostatic cooling can easily penetrate into the interface of tool-chip and develop a lubrication film. As a result, the friction in the tool-chip interface is reduced and the cutting temperature is decreased with application of dry electrostatic cooling. 


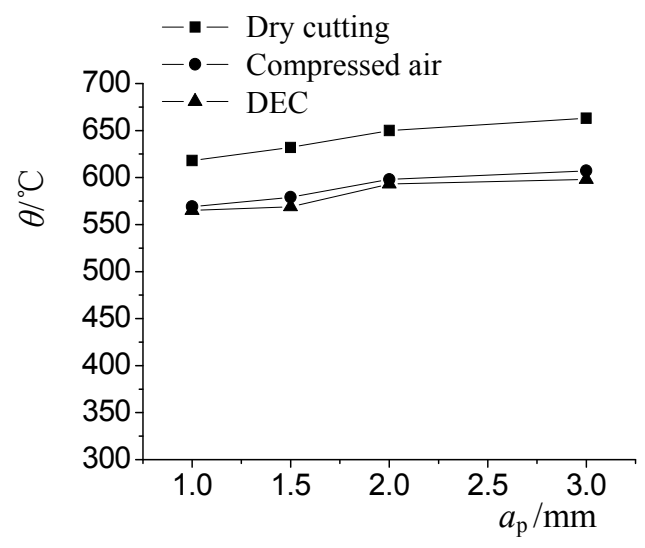

$v_{\mathrm{c}}=96.1 \mathrm{~m} / \mathrm{min}, f=0.15 \mathrm{~mm} / \mathrm{r}$

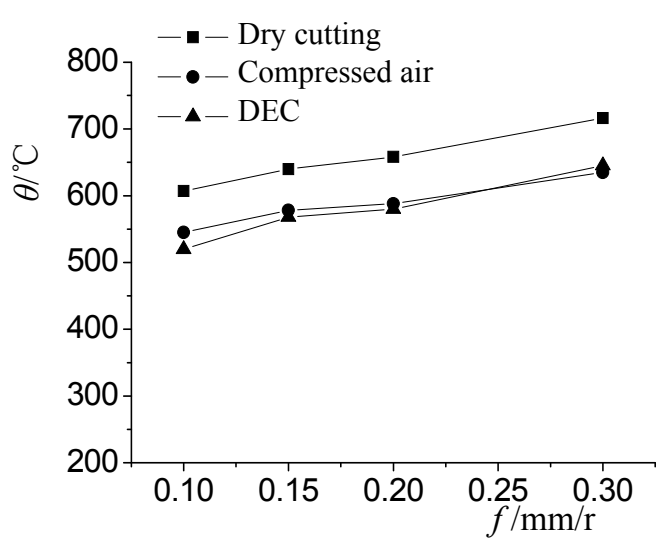

$v_{\mathrm{c}}=96.1 \mathrm{~m} / \mathrm{min}, a_{\mathrm{p}}=1.5 \mathrm{~mm}$

Fig.6 Compared with cutting temperature $\theta$

Chip formation. Fig.7 shows that the comparison of chip forms obtained at different feeds during dry electrostatic cooling, compressed air and dry cutting. It is presented that the chip is easily handled and more regular during dry electrostatic cooling. It is clear that $\mathrm{DEC}$ is advantage in forming acceptable chips. It is result from dry electrostatic cooling has the ability to reduce the cutting force and decrease the friction between the rake face of tool and chip. Fig.8 shows that the comparison of chip color obtained at different cooling conditions. It showed that the chips color was dark blue in dry cutting, orange in dry electrostatic cooling and compressed air, it indicated higher cutting temperature was obtained in dry cutting.

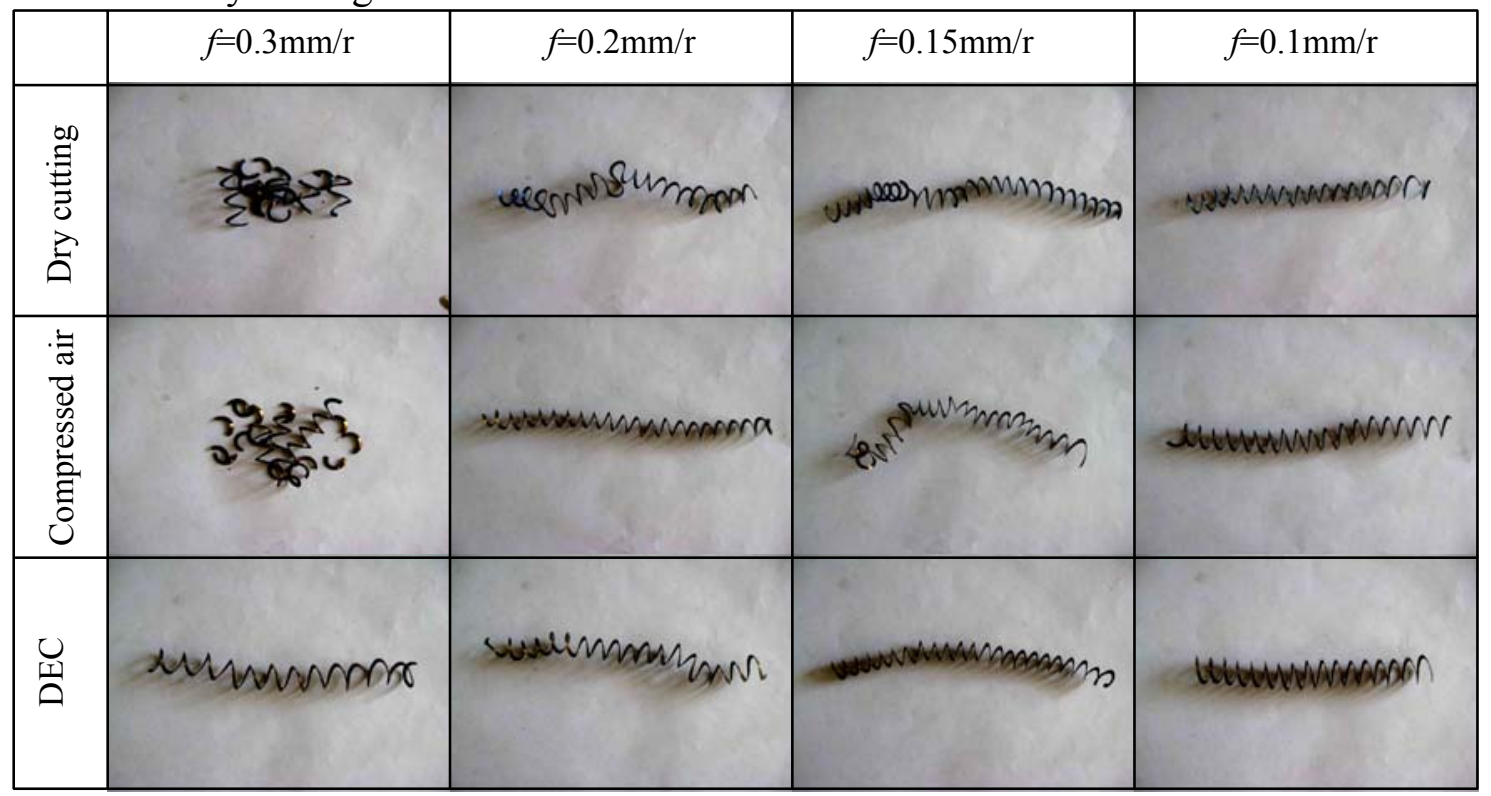

Fig.7 Compared with chip formation in different $f\left(v_{\mathrm{c}}=96.1 \mathrm{~m} / \mathrm{min}, a_{\mathrm{p}}=1.5 \mathrm{~mm}\right)$

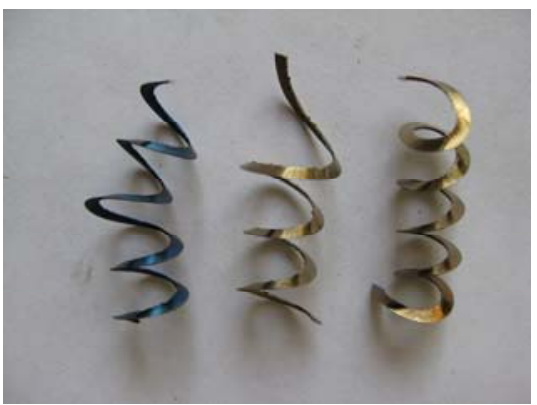

a) $f=0.15 \mathrm{~mm} / \mathrm{r}, a_{\mathrm{p}}=1.5 \mathrm{~mm}, v_{\mathrm{c}}=59.8 \mathrm{~m} / \mathrm{min}$

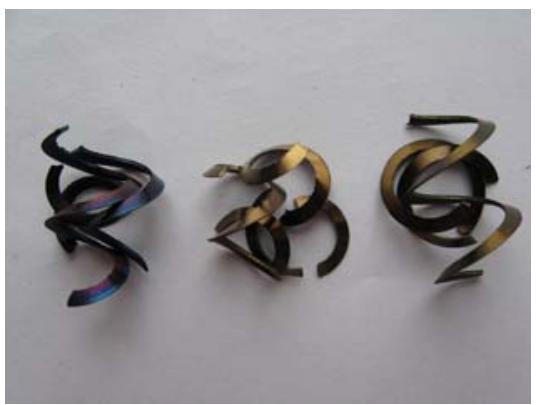

b) $f=0.30 \mathrm{~mm} / \mathrm{r}, a_{\mathrm{p}}=1.5 \mathrm{~mm}, v_{\mathrm{c}}=96 \mathrm{~m} / \mathrm{min}$

Left-Dry cutting, Middle - Compress air, Right -DEC

Fig. 8 Compared with chip colour 
Tool wear. Fig.9 shows that the tool flank wear boundary value VN when cutting AISI1045 steels in different cooling conditions.

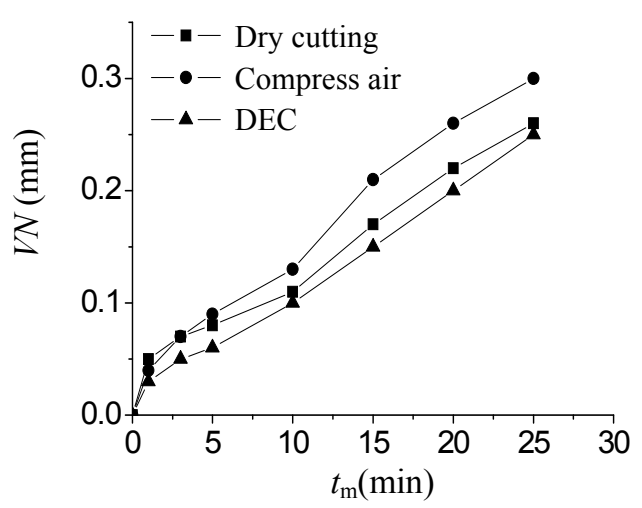

a) $v_{\mathrm{c}}=120 \mathrm{~m} / \mathrm{min}, \mathrm{f}=0.23 \mathrm{~mm} / \mathrm{r}, a_{\mathrm{p}}=1 \mathrm{~mm}$

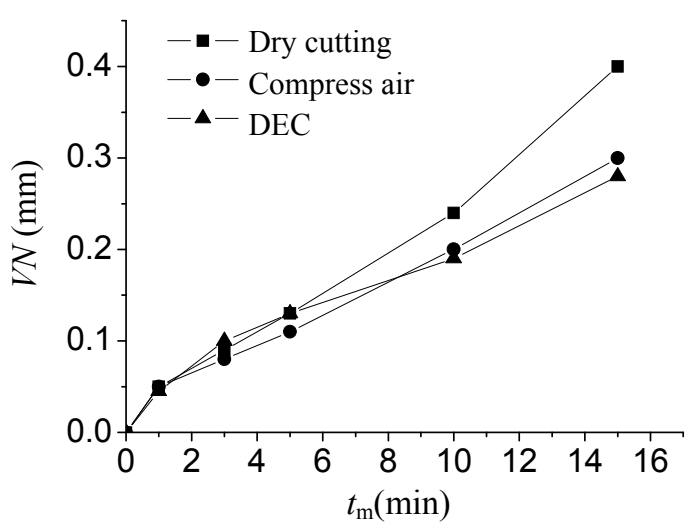

b) $v_{\mathrm{c}}=180 \mathrm{~m} / \mathrm{min}, \mathrm{f}=0.23 \mathrm{~mm} / \mathrm{r}, a_{\mathrm{p}}=1 \mathrm{~mm}$

Fig.9 The flank tool wear $V N$

It indicated that in three cutting conditions, tool wear trend was consistent. Tool flank wear in dry electrostatic cooling was slower worn than in dry cutting. It was reduced about $33 \%$ and $10 \%$ than compressed air cooling and dry cutting, respectively.

\section{Summary}

The cutting experimental investigation on dry electrostatic cooling and dry cutting in turning of AISI1045 steels with carbide tools P10 was carried out. The aim of this study was to examine the effect of dry electrostatic cooling on metal machining process. The investigation provided some conclusions as follow:

(1) The change trend of cutting force and cutting temperature during dry electrostatic cooling is similar to during dry cutting while changing the cutting parameter;

(2) With application of dry electrostatic cooling, the cutting force and cutting temperature are reduced by about $8 \%, 10 \%$ compared with dry cutting respectively, the chip deformation coefficient is lower and the chip formation is better than dry cutting;

(3) Application of dry electrostatic cooling instead of cutting fluids has the advantages of clean, eco-friendly and no recovery. It provides a new way to achieve green cutting in metal machining.

(4) Tool flank wear in dry electrostatic cooling was slower worn than in dry cutting. It was reduced about $33 \%$ and $10 \%$ than compressed air cooling and dry cutting, respectively.

\section{Acknowledgement}

This research reported in the paper is financially supported by Natural Science Foundation of Jiangsu Province, China (BK20140247) .

\section{References}

[1] E. M. Trent: Metal Cutting ( $3^{r d}$ Ed) (Butterworth, London, UK 1991).

[2] P.S. Sreejith, B.K.A. Ngoi: Journal of Materials Processing Technology. Vol.101(2000), p.287-291.

[3] N.R. Dhar, M.T. Ahmed and S. Islam: International Journal of Machine Tools \& Manufacture. Vol.47 (2007), p. 748-753.

[4] L.N. Lacalle, C. Angulo and A. Lamikiz: Journal of Materials Processing Technology. Vol. 172 (2006), p. 11-15. 
[5] S. Y. Hong: Journal of Manufacturing Science and Engineering. Vol.123 (2001), p.331-338.

[6] O. Çakır, M. Kıyak and E. Altan: Journal of Materials Processing Technology. Vol.153-154 (2004), p.35-41.

[7] J.Y. Liu, R.D. Han and Y. F. Sun: International Journal of Machine Tools \& Manufacture. Vol.45 (2005), p. 687-694.

[8] I. D. Akhmetzyanov, V. V. Bedunkevich and V. I. Ilin: Sov. Surf. Eng. Appl. Electrochem. Vol. 5(1991), p. 98-101.

[9] Y. P. Kholmogortsev: Russian Engineering Research. Vol.21(2001), p.38-42

[10] V. V. Bedunkevich: Izvestiya Vysshikh Uchebnykh Zavedenii(Russia), No. 7(2003), p. 41-47

[11]N S K Reddy and M Yang. Proc IMechE Part B: J. Engineering Manufacture. Vol. 224(2009), p.217-224.

[12]N S K Reddy, M Nouari, M Yang. InternationalJournal of Machine Tools \& Manufacture. Vol. 50(2010), p.789-797 